\title{
LAS CORTES GENERALES DE MONZÓN DE 1289, UNAS CORTES MAL ENTENDIDAS
}

\author{
THE GENERAL CORTS IN MONZÓN IN 1289, \\ A MISUNDERSTOOD CORTS
}

\author{
Vicent BAYDAL SALA ${ }^{1}$ \\ Universitat Jaume I \\ baydal@uji.es
}

\begin{abstract}
Resumen: Tradicionalmente la historiografía ha considerado que las Cortes de Monzón de 1289 fueron las primeras Generales de la Corona de Aragón y que las ordenaciones allí aprobadas afectaron de manera común cuando menos a catalanes y aragoneses. En este artículo se presentan dos novedades con respecto a dicha interpretación. Por un lado, indicamos que con anterioridad, ya en época de Jaime I, hubo otras asambleas en que se congregaron miembros de los estamentos aragoneses, valencianos, catalanes y mallorquines, aunque ciertamente estas no poseían las características que
\end{abstract}

\begin{abstract}
Historiography has traditionally considered that the Corts in Monzón in 1289 were the first General Corts of the Crown of Aragon and that the ordinances approved there commonly affected at least Catalans and Aragonese. In this article two novelties are presented regarding this interpretation. On the one hand, we indicate that previously, at the time of James I, there were other assemblies in which members of the Aragonese, Valencian, Catalan and Mallorcan estates gathered, although these meetings certainly did not possess the characteristics that later defined the General
\end{abstract}

1 El presente artículo se inserta en el marco del trabajo realizado en el proyecto «Acta Curiarum Regni Valentiae. Les actes parlamentàries medievals del Regne de València (SEJI/2019/018)», financiado por la Generalitat Valenciana y coordinado por el grupo de investigación «FORVAL. Història i Dret Forals Valencians» de la Universitat Jaume I de Castellón. 
posteriormente definieron las Cortes Generales de la Corona de Aragón. Por otro lado, mostramos que las constituciones aprobadas en Monzón en 1289 únicamente afectaron a Cataluña y Mallorca, mientras que las negociaciones político-fiscales con las comunidades de Aragón y Valencia se pospusieron para dos asambleas privativas posteriores, en Zaragoza y Valencia a lo largo de 1290.

Palabras clave: Parlamentarismo, Corona de Aragón, Alfonso el Liberal, Unión aragonesa, Monzón.
Corts of the Crown of Aragon. On the other hand, we show that the constitutions approved in Monzón in 1289 only affected Catalonia and Mallorca, while the political and fiscal negotiations with the communities of Aragon and Valencia were postponed for two subsequent privative assemblies, in Zaragoza and Valencia throughout of 1290.

Keywords: Parlamentarism, Crown of Aragon, Alfonso the Liberal, Aragonese Union, Monzón.

«Sin duda las Cortes de Monzón [de 1289] constituyen, junto con las de 1283, uno de los primeros hitos de la historia del parlamentarismo en la Corona de Aragón y un paso responsable para mejorar la relación de la Monarquía y los súbditos. "Sólo es necesario leer uno a uno los acuerdos de las Cortes de Monzón para encontrar en ellos muchos principios cuya consecuente ejecución no había de favorecer tan sólo los intereses de una de las partes, sino también robustecer de una manera conveniente la autoridad real" (Klüpfel). En ellos se materializa lo más positivo de los cambios doctrinales, políticos y sociológicos gestados en Aragón, como en todo Occidente, durante el siglo XIII; cabe afirmar que el desarrollo y resultados de esta asamblea abrieron del todo las puertas para el funcionamiento ordenado de las Cortes en el futuro, con las naturales limitaciones efectivas que sufrieron las instituciones parlamentarias en los siglos siguientes». ${ }^{2}$

Son las palabras del riguroso historiador Luis González Antón (1978: 69), uno de los máximos expertos en el parlamentarismo aragonés medieval y moderno, referentes a las primeras Cortes Generales de la Corona de Aragón desarrolladas en Monzón a finales de 1289. De hecho, es la visión que se ha mantenido sobre ellas tanto en la historiografía tradicional como en los análisis posteriores a los realizados por dicho autor, quien, no en vano, las analizó con detalle en su propia tesis doctoral (González Antón, 1975). No obstante, 
como mostraremos en el presente artículo, hasta la fecha no se ha puesto de relieve un hecho fundamental: en realidad, en aquellas Cortes únicamente se debieron aprobar unos principios de acuerdo que implicaban a los aragoneses, valencianos, catalanes y mallorquines, pero las ordenaciones aprobadas allí mismo, en la villa de Monzón, únicamente afectaban a los dos últimos grupos, los catalanes y los mallorquines, dado que los asuntos relativos a los reinos de Aragón y de Valencia se pospusieron para dos asambleas parlamentarias privativas que se celebraron durante los meses subsiguientes, a lo largo de 1290.

Asimismo, también destacaremos que ya antes de la reunión de Monzón, a finales del reinado de Jaime I, se dieron asambleas con una presencia general de súbditos de los diversos territorios de la Corona de Aragón, un fenómeno que apenas se ha destacado hasta la fecha. No obstante, siguiendo las propias observaciones del citado González Antón, cabe indicar que ciertamente la institución parlamentaria no había adquirido entonces las funciones y perfiles más definidos que fue alcanzando justo a partir de la década de 1280 .

\section{1. ¿Existieron Cortes Generales de la Corona de Aragón con anterioridad a las de Monzón de 1289?}

En 1383, prácticamente un siglo después de su celebración, Pedro el Ceremonioso, sobrino nieto del rey que las había convocado en 1289, Alfonso el Liberal, las recordaba como las primeras de su especie que habían tenido lugar, es decir, unas Cortes Generales de la Corona de Aragón con la asistencia de aragoneses, valencianos, catalanes y mallorquines: «Lo rey n'Amfós, son fill, tolch lo regne de Mallorques a son oncle e la illa de Manorcha als moros; e aquest fo lo primer que li tench a sos sotsmeses Corts Generals, e puys donà fi a les guerres de França e de Castella que li concorrien ensemps». ${ }^{3}$ Viniendo del mismo monarca que había convocado las segundas Cortes Generales de Monzón, ya en 1362, la afirmación muestra sin ambages la percepción que se tenía en la época: aquellas se identificaban como el precedente primigenio y

3 Archivo de la Corona de Aragón (ACA), Real Cancillería (RC), reg. 1278, ff. 8v-9r (4-IV-1383). Cabría la posibilidad de que el Ceremonioso se estuviera refiriendo al hecho de que durante el reinado de Alfonso el Liberal se convocaran por primera vez unas Cortes como tales, como institución definida, pero por la particularidad de la apreciación, la referencia a «sos sotmeses» y la coincidencia de dicho reinado con las Cortes Generales de la Corona de Aragón de 1289, en Monzón, pensamos que se refiere a estas últimas concretamente. 
referencial, que, asumido por todos, había pasado a los anales de la historia. Sin embargo, lo cierto es que ya antes, cuando menos en los años finales del reinado de Jaime $\mathrm{I}$, se habían reunido diversas asambleas parlamentarias a las que habían asistido conjuntamente súbditos de los diversos territorios de la Corona, como veremos acto seguido.

En concreto, la primera vez en que se puede documentar la presencia simultánea de representantes de Aragón, Cataluña y Valencia es en la convocatoria de las Cortes de Lérida para el 1 de abril de 1272 — «volumus celebrare [C]uriam in Ilerda pro aliquibus magnis negotiis, de quibus volumus loqui vobiscum et cum [a]liis baronibus et hominibus terre nostre»-, enviada a los ricos hombres aragoneses, la plana mayor de la nobleza catalana y las ciudades aragonesas (Zaragoza, Huesca, Tarazona, Calatayud, Daroca y Teruel), catalanas (Barcelona, Perpiñán, Puigcerdà, Gerona, Lérida, Tarragona y Tortosa) y valencianas (Valencia), al tiempo que sabemos de la asistencia, como mínimo, del maestre de la orden del Temple en Aragón y Cataluña, el obispo de Valencia y el abad de Poblet. ${ }^{4}$ En este sentido, la ausencia de convocatoria nobiliaria del territorio valenciano es plenamente concordante con la situación del momento, ya que su estamento militar, dominado por los barones de procedencia aragonesa, se negaba a legitimar la institucionalidad del reino de Valencia, como había mostrado en las recientes Cortes valencianas de 1271, en las que se había negado a sustituir los Fueros de Aragón por los de Valencia en sus señoríos y a llegar a ningún tipo de acuerdo con Jaime I —como sí que lo había hecho el estamento real - en torno a la confirmación de las tierras repartidas y traspasadas durante el proceso de conquista a los musulmanes (Baydal, 2014: 194-201).

De hecho, el acuerdo entre el monarca y los «nobilibus sive richis hominibus et militibus ac infantionibus habitantibus et hereditates seu possessiones habentibus in regno Valentie» se produjo precisamente en las mismas Cortes de Lérida de 1272, con el reconocimiento real de la plena validez de las posesiones de la nobleza a cambio del pago conjunto de 20.000 sueldos, ${ }^{5}$ reafirmando, a su vez, la negativa de dicho estamento a operar dentro de un marco político y parlamentario propiamente valenciano. En todo caso, aquella no era la princi-

4 La convocatoria en: ACA, RC, reg. 18, f. 89v (1-III-1272). La presencia de los miembros de la Iglesia, respectivamente en: ACA, RC, reg. 310, f. 56v-57r (25-IV-1272); Archivo de la Catedral de Valencia (ACV), Pergaminos, núm. 4655 (8-IV-1272); Archivo Histórico Nacional, Clero, Poblet, Carpeta 2.277, núm.10 (20-IV-1272).

5 ACV, Pergaminos, núm. 6.001 (18-IV-1272). 
pal materia a tratar en la asamblea, sino que lo era un posible ataque del rey de Francia y, sobre todo, el intento de pacificación de la lucha que mantenían el infante Pedro - futuro Pedro el Grande - y su hermanastro y rico hombre aragonés Fernando Sánchez de Castro, que se resolvió momentáneamente con la destitución del primero del cargo de procurador general de los reinos de la Corona (Soldevila, 1956: 319-322; González Antón, 1978: 50). No en vano, este mismo tipo de asambleas, convocadas por asuntos urgentes y muy concretos, a las que asistían algunos de los principales miembros de los estamentos de los diversos territorios se repitieron a lo largo de los años sucesivos.

Es lo que al parecer ocurrió, por ejemplo, en las Cortes de Alzira-Valencia de noviembre a diciembre de 1273 , congregadas nuevamente por la disputa entre el infante Pedro y Fernando Sánchez de Castro, que había derivado en un grave conflicto del primero con el padre de ambos, Jaime I. En relación con ello, sabemos que, según relata él mismo en el Llibre dels fets, el rey convocó a los principales prelados, nobles y prohombres urbanos de Aragón y de Cataluña — «manam nostra Cort a Algezira a l'arquebisbe e als bisbes e als rics hòmens e als bons hòmens de les viles, quatre de cada una»- $\mathrm{y}$, aunque no haya constancia explícita de la participación valenciana más allá del obispo de Valencia - «havíem ja manada la Cort, que fossen a Algezira, e era vengut l'infant don Jaime e l'arquebisbe e els bisbes (lo de Barcelona e el de Lleida e lo de València) e Garcia Ortiz e do Artal de Luna, e de les ciutats de Lleida e de Saragossa e de Terol e de Calataiú e dels altres 1locs» (Soldevila, 2007: 494495) _ , es bastante probable que, además de nobles catalanes y aragoneses que tenían señoríos en el territorio valenciano, también se encontraran presentes los síndicos de la ciudad de Valencia, dada la ubicación geográfica de la reunión.

Fuese como fuese, lo cierto es que las Cortes estaban constituidas en Alzira a mediados de noviembre y continuaban allí a principios de diciembre, ${ }^{6}$ aunque parece que la última sesión, en torno al 13 de diciembre, se celebró en la ciudad de Valencia — «Curie nostre quam nuper apud Valentiam mandaveramus»_, según apuntan las cartas enviadas por Jaime I a los principales prelados y ciudades de Aragón y Cataluña cuando estos ya habían abandonado la reunión: «post recessum dicte Curie». ${ }^{7}$ En ellas se indicaba que la asamblea

6 Así lo muestran diversos documentos del momento dados «in Curia constitutis»: ACA, RC, reg. 19, ff. 74r (12-XI-1273) y 81v (7-XII-1273).

7 ACA, RC, reg. 18, ff. 53v (15-XII-1273) y 75v (15-XII-1273). La estancia del rey en Valencia se comprueba en: ACA, RC, reg. 19, f. 82r (13-XII-1273). 
había finalizado sin resolución alguna sobre la rebelión del infante, aunque poco después se produciría la reconciliación entre padre e hijo, lo que acabaría desembocando a lo largo de 1274 en una revuelta contra ambos de la nobleza catalana, encabezada por el vizconde de Cardona y el conde de Ampurias, y de la aragonesa, liderada precisamente por Fernando Sánchez de Castro, «porque crebantades a aragoneses fueros e costumes d'Aragón e a catalanes costumes e usatges de Catalunya» (Fondevilla, 1913: 1143). En este contexto el monarca volvió a convocar nuevamente una Corte en la que se puede documentar conjuntamente a miembros de los diversos estamentos catalanes y aragoneses - pero no valencianos - tanto en marzo de 1275 en Lérida — donde también estaban presentes los prohombres de la ciudad de Mallorca-como en noviembre del mismo año en dicha ciudad, después de que el infante hubiese acabado con la vida de su hermanastro (Soldevila, 1956: 369-401). ${ }^{8}$

Asimismo, unos pocos meses más tarde, muy probablemente para intentar responder al alzamiento musulmán que se estaba produciendo en el territorio valenciano - «negotium secretissimum quod cedit ad magnum Dei servitium»—, Jaime I tuvo que requerir urgentemente la presencia en la ciudad de Valencia cuando menos de los principales prelados de Aragón, Cataluña y Mallorca, y de un buen grupo de nobles catalanes y aragoneses, ${ }^{9}$ a los que tal vez se añadieran el obispo de Valencia o los dirigentes de la propia capital valenciana, que posiblemente se encontraban junto al monarca en aquellos momentos, por lo que no precisaban de cartas de convocatoria específicas. Lo cierto, en cualquier caso, es que, como ya apuntó en su día Sylvia Romeu (1970), la asamblea se celebró de manera efectiva en marzo de 1276, según constata una orden para reforzar la frontera «donec presens Curia fuerit celebrata in Valentia». ${ }^{10}$

En conjunto, pues, desde la reunión de Lérida de abril de 1272 hasta el final del reinado de Jaime I a mediados de 1276 se congregaron sucesivas asambleas generales con el nombre de «Curia»o «Cort» en las que participaron simultáneamente miembros de los estamentos de los diversos territorios, por lo que tal

8 Los prohombres mallorquines recibieron diversos privilegios en la primera de aquellas reuniones en Lérida: ACA, RC, reg. 26, ff. 72r-75r (12-III-1275). Por otra parte, además de nobles catalanes y algunos prelados y ciudades aragonesas, a aquella misma asamblea de marzo de 1275 también fueron convocados numerosos alcaides de castillos y bailes reales del reino de Valencia para que rindieran cuentas de su administración: ACA, RC, reg. 23, f. 15v (12-II-1275). No obstante, no hay constancia documental de que fueran convocados miembros de los estamentos valencianos propiamente dichos.

9 ACA, RC, reg. 23, f. 34r (3-II-1276).

10 ACA, RC, reg. 23, f. 35v (4-II-1276). 
vez podríamos considerarlas Cortes Generales de la Corona de Aragón. Con todo, la apreciación ulterior que hemos apuntado de Pedro el Ceremonioso parece indicar que, a pesar de ello, dichas reuniones no tuvieron las mismas características o cuando menos consideración que la que posteriormente convocó Alfonso el Liberal en 1289 y más tarde el propio Ceremonioso en 1362 , 1376 o 1383. En este sentido, parecen oportunas las indicaciones de Luis González Antón (1979) sobre la «evolución preparlamentaria» del reinado de Jaime I, calificando las reuniones que tuvieron lugar durante dicho período como «asambleas de Corte» y estimando, pues, que las Cortes aún no habían definido las formas y características que las irían convirtiendo en una institución de manera plena a finales del siglo XIII, durante los reinados de Pedro el Grande, Alfonso el Liberal y Jaime II. De hecho, aquellas reuniones de la década de 1270 se asemejan más a lo que posteriormente, en época del mismo Jaime II, recibiría el nombre de «Consilium Generalem», con la convocatoria de los principales «prelatorum, nobilium et civium» de la Corona para consultarles sobre una materia muy determinada, como sucedió en 1319, ante la negativa del infante Jaime a casarse en Gandesa, o en 1324, ante la muerte del rey Sancho de Mallorca y la posible intervención del monarca aragonés. ${ }^{11}$

En definitiva, pues, cabría descartar la consideración de Cortes Generales de la Corona de Aragón de dichas asambleas del reinado de Jaime I, ya que serían diferentes a las que posteriormente se convocarían en Monzón a partir de 1289 . No obstante, también hay que tener en cuenta que esta misma reunión tuvo ciertas particularidades que hasta ahora no se han destacado — dado que el propio Luis González Antón las pasó por alto- y que transforman notablemente la comprensión de lo que allí sucedió, como expondremos a continuación.

\section{Más allá de Monzón: el ciclo de asambleas parlamentarias de 1289-1290}

Tras un largo intervalo inicial en el que Pedro el Grande, en consonancia con su talante autoritario (Cingolani, 2010), únicamente convocó una asamblea parlamentaria —en 1281 en el reino de Valencia para introducir una pe-

11 Sobre la reunión de 1319 véanse: Archivo Municipal de Valencia, Manuales de Consejo, A-1, f. 144r-v (26-IX-1319); ACA, RC, reg. 245, f. 198v (22-X-1319). Sobre la de 1324: ACA, RC, reg. 308, f. 260v; Santamaría (1982). 
queña reforma foral, «in Generali Curia, de assensu et voluntate nobilium, religiosorum, militum, civium et omnium aliorum hominum proborum congregatorum in dicta Curia» (Romeu, 1969) —,${ }^{12}$ los acontecimientos sucedidos a partir de 1283, tras su regreso de la campaña de ocupación de Sicilia y el estallido de la revuelta aragonesa de la Unión, serán los que, sin embargo, acabarán poniendo las bases de una relación política estable entre la Corona y los territorios cismarinos sustentada en las Cortes (González Antón, 1975; Sabaté, 2009). No en vano, las consecuencias de los dos hechos citados motivaron un extenso período, hasta el final del reinado de Alfonso el Benigno en 1291, caracterizado por la guerra prácticamente permanente contra enemigos exteriores, como los reyes de Francia, Navarra, Mallorca y Castilla, y por los enfrentamientos bélicos en el interior, especialmente entre el monarca y los unionistas aragoneses y entre estos y el estamento real valenciano, a causa de la disputa por la aplicación de los Fueros de Aragón - y su posible sustitución por los de Valencia - que hemos comentado con anterioridad. De hecho, este contexto general fue el que acabó motivando la convocatoria de las Cortes Generales de Monzón. ${ }^{13}$

En concreto, las reivindicaciones de la Unión - encabezada por la nobleza aragonesa, con el apoyo inicial de numerosas ciudades y villas del reino- se plasmaron en el Privilegio General obtenido de Pedro el Grande en una asamblea celebrada en Zaragoza en octubre de 1283, con el que pretendían asegurarse toda una serie de poderes jurisdiccionales y económicos, controlando a su vez las actuaciones del rey a través de la confirmación del Justicia, el nombramiento del Consejo real y la celebración de una «Cort General de aragoneses en cada un ayno». ${ }^{14}$ Pero, además, otra de sus demandas básicas era el mantenimiento de los Fueros de Aragón y las inmunidades señoriales vinculadas a ellos en los señoríos del territorio valenciano pertenecientes a la nobleza de procedencia aragonesa, por lo que simultáneamente también obtuvieron un Privilegio General en dicho sentido destinado a los «richis hominibus, militibus et aliis et omnibus illis de regno Valentie qui foros Aragonie habere voluerint». ${ }^{15}$ Sin embargo, ello chocaba frontalmente con los intereses de la

12 ACV, Códex 146, ff. 3rv.

13 Para los hechos que sintetizaremos a continuación, desde finales de 1283 a principios de 1289, véanse: Zurita (1610), Carreras (1921), Soldevila (1955), Soldevila (1963), Gallofré (1968), Romeu (1970), Romeu (1972), González Antón (1975), Palacios (1975) y Baydal (2014).

14 Real Academia de la Historia, Colección Salazar, Manuscrito M-139, f. 10r (3-X-1283), transcrito por González Antón (1975: doc. 1).

15 ACA, RC, reg. 47, ff. 53r-54r (3-X-1283), transcrito por Romeu (1972: 108-111). 
inmensa mayoría del estamento real valenciano, que deseaba extirpar dichas prerrogativas nobiliarias del reino, por lo que, para obtener su ayuda económica, el monarca se tuvo que reunir de inmediato, entre noviembre y diciembre de 1283 , con la ciudad de Valencia y proceder a la confirmación de la exclusividad territorial de los fueros valencianos y a la concesión del Privilegium Magnum, con abundantes libertades dirigidas a la propia capital y el resto de villas. Finalmente, el conjunto de estamentos catalanes también aprovechó la situación para fortalecer su autoridad a través de las constituciones aprobadas en las Cortes de Barcelona de diciembre de 1283 y del Recognoverunt proceres otorgado a dicha capital, al tiempo que establecieron igualmente la celebración anual de asambleas parlamentarias en Cataluña para tratar «de bono statu et reformatione terre». ${ }^{16}$

En dicho contexto, tras la inesperada muerte de Pedro el Grande a finales de 1285 y el acceso al trono de su hijo Alfonso el Liberal, el joven rey trató de contemporizar en un principio, pero finalmente no pudo evitar el estallido de la guerra entre los unionistas y el estamento real valenciano a principios de 1287 y un nuevo alzamiento de los primeros, que no pudo ser pacificado hasta la concesión a finales de año de los Privilegios de la Unión, que reforzaban las aspiraciones planteadas al inicio de la revuelta, con el control del poder a través de las Cortes y del Consejo real y la validez de los Fueros de Aragón en el reino de Valencia. Así pues, el monarca pasó los primeros meses de 1288 preeminentemente en tierras aragonesas, disponiendo medidas relacionadas con la aplicación de dichos privilegios hasta que a finales de mayo se trasladó a Cataluña para combatir las entradas por el noreste de Jaime II de Mallorca, quien se retiró durante el mes de julio. Por entonces Sancho IV de Castilla intervino también en el juego de relaciones internacionales de la Corona de Aragón, tras firmar un pacto de ayuda mutua con Felipe IV de Francia y ofrecer a Alfonso el Liberal el matrimonio con su hija Isabel y el reino de Murcia, a cambio de que le librara a sus sobrinos, los infantes de la Cerda, que pretendían su trono. Sin embargo, el monarca aragonés, lejos de aceptar el ofrecimiento, reaccionó contra el acuerdo castellano-francés proclamando a Alfonso de la Cerda rey de Castilla, en septiembre de 1288 en Jaca, pactando con Eduardo I de Inglaterra la liberación del príncipe de Salerno, Carlos II de Anjou — que estaba en su poder-, y enviando a finales de año una carta de desafío a Sancho IV, con lo que acabó estallando la guerra entre ambos monarcas. 
Así las cosas, tras dichas iniciativas decididas de manera unilateral y el hecho de que no se convocaran las preceptivas Cortes de Aragón en el mes de noviembre, la Unión reavivó su presión y el rey tuvo que reunirse con sus miembros en Zaragoza en marzo de 1289. En dicha asamblea los unionistas amenazaron con librar los castillos que estaban en su poder a un soberano extranjero, al tiempo que volvieron a reivindicar la validez del fuero aragonés en el territorio valenciano, proponiendo una alternancia anual de oficiales de justicia urbanos y caballeros, así como la elección definitiva de un fuero u otro mediante la convocatoria de Consejos generales en cada localidad, con la presencia de dos caballeros de la Unión, para tomar una decisión al respecto. Sin embargo, aunque la respuesta de Alfonso el Liberal a dichos planteamientos fue afirmativa — «complir e seguirlos en todo»—, no se conoce su aplicación práctica y, de hecho, las demandas de la asamblea unionista fueron in crescendo, confirmando a final de mes a los miembros del Consejo del rey y procediendo a escoger a los oficiales de la propia casa real. Asimismo, dado que «el senyor rey non puede agora andar en el regno de Valençia por raçón de la guerra de Castiella e por raçón de su flaqueça por complir el fuero de Aragón», reclamaron que les cediese los castillos de Morella y Morvedre y que hiciese jurar a los oficiales reales del territorio valenciano la plena observancia de las leyes aragonesas, ya que, en caso contrario, comenzarían sus ataques contra «los rebelles del regno de Valençia». ${ }^{17}$

Ante tales amenazas y la situación de emergencia bélica, Alfonso el Liberal reaccionó el 24 de abril de 1289, todavía en Zaragoza, convocando para dos meses después, el 24 de junio, unas Cortes en Monzón, a las que debían asistir nobles, eclesiásticos y prohombres de las universidades reales de Aragón y de Cataluña - al parecer, sin presencia valenciana - para tratar sobre «iustitia observanda ac statu terre nostre pacifico et tranquillo, ac pro defensione regnorum nostrorum». ${ }^{18}$ Sin embargo, el texto de las cartas de convocatoria aparece rayado por completo en el registro correspondiente de la cancillería y, de hecho, el monarca no se desplazó a Monzón hasta el 9 de octubre de 1289 (Carreras, 1921: 77). Por lo tanto, parece que la llamada fue cancelada a causa del enfrentamiento bélico con el rey de Castilla, como apunta el hecho de que aquellas mismas cartas, «tam pro Curia quam pro exercitu»,

17 Real Academia de la Historia, Colección Salazar, Manuscrito M-139, f. 123r (25-III-1289), transcrito por González Antón (1975: doc. 95).

18 ACA, RC, reg. 79, f. 33r (24-IV-1289), transcrito por González Antón (1975: doc. 255). 
ordenaban al mismo tiempo la formación de huestes ante la congregación de ejércitos extranjeros «proponentes intrare et invadere terram nostram». ${ }^{19} \mathrm{En}$ este sentido, como afirma Luis González Antón, no se ha encontrado otra convocatoria posterior de Cortes, pero, a diferencia de este autor, pensamos que aquel documento cancelado no puede ser utilizado para analizar los asistentes a la reunión, ya que, por una parte, el hecho de que a la vez se pidiera la formación del ejército motivó el envío de misivas a muchos pequeños núcleos que probablemente no debían acudir a la asamblea y, por otra parte, como explicaremos a continuación, sabemos que la asamblea finalmente celebrada entre octubre y noviembre de 1289 tuvo otra convocatoria general, que no se ha conservado o que no conocemos.

En definitiva, los choques militares producidos entre abril y septiembre obligaron a posponer la asamblea prevista. En primer lugar, tras haberla convocado, sabemos que el rey Alfonso se desplazó hacia la frontera con Castilla, a Calatayud, desde donde a finales de junio realizó una incursión, junto a Alfonso de la Cerda, contra la cercana Almazán. ${ }^{20}$ Por lo tanto, la proyectada reunión de Monzón, justo para aquellas fechas, no se pudo celebrar, como tampoco a lo largo del verano, ya que, según apunta Zurita (1610: Libro IV, cap. 109), el monarca tuvo que abandonar urgentemente las tierras castellanas y aragonesas «porque tuvo nueva cierta que gentes de Francia y del rey de Mallorca entraban contra Cataluña por el condado de Rosellón». Y, en efecto, el monarca se trasladó al territorio catalán en agosto, dirigiéndose directamente a la Cerdaña, donde a finales de mes asedió el castillo de Vall de Ribes hasta que consiguió alejar a las huestes enemigas (Carreras, 1921: 76). Por entonces, además, el príncipe de Salerno, Carlos II de Anjou, había sido coronado en Roma como rey de Sicilia y Alfonso el Liberal tuvo que iniciar también los preparativos para la guerra marítima. Finalmente, pasó el mes siguiente en Barcelona, desde donde el 6 de septiembre, como ya apuntó Antonio de la Torre (1923: 34) a partir del contenido de un privilegio dirigido a dicha ciudad, canceló una convocatoria previa de Cortes que había realizado en ex-

19 ACA, RC, reg. 79, f. 33v (24-IV-1289), transcrito por González Antón (1975: doc. 255).

20 Zurita (1610: Libro IV, cap. 109) afirma que la retirada de Castilla por parte de Alfonso el Liberal se produjo a mediados de julio, pero, según se comprueba en el itinerario realizado por Carreras (1921: 76) y en la documentación de cancillería, sabemos que a principios de dicho mes el rey ya se encontraba en Zaragoza. De hecho, la incursión del monarca debió durar simplemente del 27 de junio al 1 de julio, los días en que no se conoce su lugar de estancia, una conjetura reforzada por la fecha de la concesión secreta del reino de Murcia por parte de Alfonso de la Cerda, el 26 de junio todavía en Calatayud, seguramente justo antes de entrar en tierras castellanas. 
clusiva a los estamentos catalanes para mediados de mes y los citó, junto a los aragoneses, otra vez en Monzón para el día 29, ${ }^{21}$ donde la asamblea debió de tener lugar entre el 9 de octubre, día de la llegada del rey, y el 7 de noviembre de 1289, fecha de la firma de las constituciones aprobadas (Carreras, 1921: 77; González Antón, 1975: doc. 263).

Por lo tanto, como ya había pasado en abril, parece que los valencianos no quedaban a priori incluidos en la convocatoria, aunque sabemos a ciencia cierta que sí que acudieron representantes de la ciudad y las villas reales del reino de Valencia, según muestra una misiva que el rey les envió el 9 de noviembre, justo tras el cierre de la asamblea. ${ }^{22}$ En ella informaba a los justicias, jurados, consejeros y prohombres del realengo que iría a tierras valencianas a mediados de febrero de 1290 para tratar sobre las «altercationes» que los «probi homines per vos transmissi apud Montesonum ad nostram Curiam Generalem» habían mantenido «cum baronibus, militibus ac civibus regni Aragonum ratione fori Aragonum, quem in regno Valentie asserunt se habere». ${ }^{23}$ Asimismo, la promesa realizada por los síndicos de la ciudad de Valencia de avanzar el pago del monedaje que correspondía a 1291 confirma plenamente la presencia valenciana en la reunión. ${ }^{24}$ En consecuencia, ciertamente la asistencia a las Cortes de Monzón implicó a todos los territorios de la Corona, aunque, como explicaremos a continuación, no sucedió lo mismo con las constituciones que allí se firmaron, que hacían referencia exclusiva a los catalanes y los mallorquines.

\subsection{Las Cortes catalanas de Monzón (octubre-noviembre de 1289)}

Las constitutiones aprobadas en Monzón muestran la firma de representantes catalanes y mallorquines, al tiempo que también aparecen testigos arago-

21 El 6 de septiembre de 1289 el rey revocó la convocatoria de Cortes catalanas en Barcelona «pro eo quare negotia pro quibus Curiam celebrare intendimus tangunt omnes de dominatione nostra, tam aragonensis quam cathalanos», según consta en dicho privilegio: ACA, Colecciones, Consejo de Ciento, Pergaminos, núm. 406 (6-IX-1289).

22 De hecho, es posible que los valencianos quedaran incluidos en aquél «omnes de dominatione nostra, tam aragonensis quam cathalanos», que hemos citado en la nota anterior, dado que a finales del siglo XIII aún no se había formado un gentilicio colectivo propio para los habitantes cristianos del reino de Valencia, que continuaban recibiendo el nombre de catalanes o aragoneses, en función de su procedencia territorial (Baydal, 2016).

23 ACA, RC, reg. 80, f. 93r (8-XI-1289), transcrito por González Antón (1975: doc. 266).

24 La promesa fue realizada a mediados de octubre, al poco de llegar el rey a Monzón: ACA, RC, reg. 80, f. $69 \mathrm{r}(15-\mathrm{X}-1289)$ 
neses y se explicita que el rey las había ordenado con consejo, asentimiento y voluntad de eclesiásticos, nobles y ciudadanos de los regnorum nostrorum..$^{25}$ Pero, en cualquier caso, eran precisamente eso: constituciones catalanas, no fueros aragoneses ni valencianos. De hecho, las constitutiones Curie Montissoni nunca pasaron a los cuerpos jurídicos de los reinos de Aragón o de Valencia, y no las encontraremos en ninguno de sus libros de privilegios o códigos forales, justo lo contrario que pasa con los catalanes, ya que están incluidas tanto en el Llibre verd de Barcelona como en las compilaciones de las Constitucions $i$ altres drets de Catalunya. Así pues, todo aquello oficialmente promulgado en Monzón en 1289 afectaba única y exclusivamente a Cataluña y al reino de Mallorca, de manera que en absoluto eran unas disposiciones que estuvieran dirigidas al conjunto de la Corona de Aragón o, ni tan solo, a los catalanes y los aragoneses.

En este sentido, parece que Luis González Antón (1975: 246, 253) intuyó alguna cosa al respecto, ya que advirtió que «no hay nada o casi nada puramente aragonés en su texto» y que «muchas de las opiniones relativas a estas Cortes deben considerarse como completamente provisionales», aunque finalmente consideró que las constituciones también afectaban a Aragón y que tal vez existiera una copia desconocida enviada a los aragoneses. Al respecto, seguramente dicho autor interpretó que algunas de las disposiciones no podían estar dirigidas más que al territorio aragonés, como las que, según decía, establecían que los oficiales no podrían recibir «rentas de ninguna honor», que «no será acatada ninguna carta contra el Privilegio General [de Aragón de 1283]» o que serían revocadas las donaciones realizadas desde el inicio del reinado mediante la instauración de un nuevo Consejo real, «objetivo por el que tanto había batallado la Unión» (González Antón, 1975: 247, 252). No obstante, al analizar dichas ordenaciones se observa que la primera de ellas se refería simplemente a la recepción de otras rentas diferentes al salario de los oficiales - no a las honores aragonesas en concreto-, mientras que la segunda hablaba de la invalidez de las órdenes reales dadas contra privilegium generali vel speciale, vel contra consuetudines generales vel speciales - no del Privilegio General de Aragón-y la última, referente a la revocación de las donaciones y el establecimiento de un nuevo Consejo real, no era una reivindicación exclusivamente aragonesa, sino también de los nobles catalanes, por

25 Las constituciones en: ACA, RC, reg. 80, ff. 132r-135v (7-XI-1289), transcritas por González Antón (1975: doc. 263). Véanse allí las citas realizadas a continuación. 
lo que es lógico que apareciera en las constituciones aprobadas para Cataluña, con el objeto de proceder a tales restituciones; de hecho, como el propio González Antón indica (1975: 253, 410), los consejeros reales escogidos en Monzón «son todos catalanes». ${ }^{26}$

El resto de capítulos no mencionaba en absoluto a los aragoneses, pero, en cambio, sí que confirmaba o precisaba diversas disposiciones catalanas anteriores, como la tasación de las cartas de escribanía o el modo de contribución en las «questiis et comunibus et aliis exactionibus» de los poseedores de tierras dentro de los términos de los castillos, según las constituciones aprobadas en las Cortes de Cataluña de 1283, ratificando, además, todas las que allí promulgó Pedro el Grande, «in Curia Generali Barchinone», excepto, precisamente, las que ahora quedaban alteradas por nuevas decisiones: «salvo toto eo quod in presenti Curia est ordinatum». Además, comparándolas con aquellas y con las posteriores, se aprecia que el conjunto de constituciones de 1289 se inscribe en el mismo contexto catalán iniciado entonces y continuado con Jaime II: se defendían las inmunidades eclesiásticas — lo que no pasaba todavía en las Cortes aragonesas ni en las valencianas-; se compensaba a los señores por los abusos reales cometidos; se consolidaba lo que posteriormente seria la remença; y, sobre todo, como ya había pasado en 1283, se daban numerosas constituciones destinadas a delimitar las facultades de los oficiales reales y ofrecer garantías para conseguir un ejercicio correcto de sus cargos. En definitiva, todas y cada una de aquellas constituciones eran válidas privativamente para Cataluña y el reino de Mallorca — para el que había ciertas disposiciones específicas -,${ }^{27}$ de manera que, a pesar de haber sido dadas con el «consilio, assensu et voluntate» de los eclesiásticos, nobles y ciudadanos de todos los «regnorum nostrorum», solo los miembros de los estamentos de Cataluña y los prohombres de la ciudad de Mallorca prometieron «tenere, complere et observare» los capítulos aprobados.

De hecho, precisamente por ello, el mismo día de la publicación de las constituciones, el 7 de noviembre de 1289, únicamente los catalanes y los

26 Por ejemplo, en junio de 1290 en Barcelona, cinco magnates catalanes actuaban como testigos del traspaso de ciertos bienes del rey a Pere Dessoler, «de consilio consiliariorum nostrorum», dentro de aquel proceso de redistribución de las donaciones realizadas: ACA, RC, reg. 83, ff. 67v-68r (10-VI-1290).

27 Se prohibía la enajenación o división del reino de Mallorca, y su unión a Aragón o Cataluña, y se confirmaban los privilegios generales dados por el rey a Mallorca, Menorca e Ibiza, aunque se revocaban los privilegios, donaciones y alienaciones personales, excepto en el caso del reparto de las tierras menorquinas. 
mallorquines aprobaron la concesión de una ayuda trienal «pro defensione terre nostre in guerra, scilicet quam habemus cum rege Francie et cum rege Castelle et cum principi Salerni», que se recaudaría a partir de la Navidad de aquel año en todas las señorías de Cataluña y las islas de Mallorca, Menorca e Ibiza. Así, casi exactamente el mismo grupo de cuarenta y ocho nobles - excepto dos-y de veintiocho prohombres urbanos de catorce ciudades y villas que habían firmado las constituciones dieron también su conformidad al subsidio, según consta en la carta de indemnidad correspondiente. ${ }^{28}$ No obstante, apenas conocemos datos sobre dicha contribución, ya que la mencionada concesión, que establecía que la ayuda quedaría cancelada si finalizaba la guerra, únicamente hablaba de «certum auxilium», que debía ser recaudado y recibido por «petitores et levatores, secundum formam taxatam et ordinatam». En cualquier caso, posiblemente se trataba de una sisa o imposición indirecta general en los mercados locales como la que ya se había aprobado un año antes en los dominios reales y eclesiásticos de Cataluña (Sánchez, 1995: 59-64), según apunta un documento que hacía referencia al dinero dado por los clavarios de la colecta realizada «ratione auxilii sive sise». ${ }^{29}$

Por otra parte, sabemos que los habitantes de Lérida se negaron a otorgar el subsidio - «cum populares eiusdem civitatis nobis contradicerent in predictis»—, de manera que el 15 de noviembre, unos pocos días después de cerrar las Cortes, el rey se desplazó a la localidad del Segre para congregar un parlamentum en que expuso las causas por las que consideraba necesario que accedieran a pagarlo..$^{30}$ En efecto, ningún prohombre de Lérida había firmado ni las constituciones de Monzón ni la carta de indemnidad de la ayuda monetaria, como tampoco lo habían hecho los de Cervera. Además, es factible que dicha insumisión estuviese relacionada con la guerra entre los Montcada y los Entenza - con dominios en la zona-, desencadenada durante la campaña militar de aquel verano en la Cerdaña y que llegó a su punto álgido precisamente a finales de 1289 y principios de 1290 (Zurita, 1610: Libro IV, cap. 117). De hecho, Alfonso el Liberal, tras la fracasada reunión con los leridanos en la segunda quincena de noviembre se trasladó a Barcelona, pero entre ene-

28 Aunque el grupo de nueve eclesiásticos y los dos síndicos de la ciudad eclesiástica de Tarragona que habían aprobado las constituciones no aparecen en la firma de dicha carta - tal vez por discrepancias al respecto-, el texto de la aprobación dejaba claro que el subsidio también se pagaría en los lugares de la Iglesia. Véase el documento en: ACA, RC, reg. 83, ff. 8r-10r (7-XI-1289), transcrito por Sánchez y Ortí (1997: doc. II).

29 ACA, RC, reg. 83, f. 92r (27-X-1290).

30 ACA, RC, reg. 80, f. 126r (1-XII-1289). 
ro y mediados de febrero de 1290 tuvo que regresar y estuvo moviéndose entre Alcoletge, Corbins, Gardeny y Lérida (Carreras, 1921: 78), seguramente para intervenir en dicho conflicto o para imponer la aceptación de las constituciones aprobadas en las Cortes y el pago del subsidio, según explicitan diversas convocatorias de hueste a ciertos nobles y lugares del sur de Cataluña. ${ }^{31}$ En este sentido, sabemos que finalmente los habitantes de Lérida acabaron contribuyendo en el auxilio monetario, como confirma el hecho de que unos meses más tarde el rey les otorgara una prórroga del siguiente monedaje, después de que los clavarios ordenados en Monzón «tradiderunt nobis de presenti, de denariorum auxilii Ilerde, viginti millia solidos iaccenses». ${ }^{32}$

\subsection{Las Cortes aragonesas de Zaragoza (febrero-marzo de 1290)}

El rey había prometido a los prohombres del estamento real valenciano que iría a su reino a mediados de febrero de 1290 para abordar sus disputas con los nobles aragoneses, pero, como acabamos de ver, en esa fecha se encontraba en torno a Lérida, desde donde posteriormente se trasladó a Zaragoza. Al parecer, pues, las luchas en la zona habían demorado las previsiones de Alfonso el Liberal, quien, de hecho, el 17 de enero ya había escrito a los principales barones aragoneses con dominios valencianos — Jaime Pérez, Jaime de Jérica, Pedro de Ayerbe y Pedro Fernández de Híjar - para informarles de que el procurador del propio Jaime Pérez, es decir, Bernardo Guillén de Entenza, y el procurador de los nobles, caballeros e infanzones del territorio valenciano, Juan de Vidaurre, habían aceptado una prórroga «super facto regni Valentie» hasta que el rey celebrara una «Curiam in Cesaraugusta», por lo que les había cedido en rehenes al conde de Pallars Ramon Roger y a los nobles Ato de Foces, Ramon de Anglesola y Berenguer de Bellvís, que permanecerían dentro de los muros de Segorbe hasta que el monarca acudiera a Valencia para tratar dicho asunto. ${ }^{33}$ Así pues, aquella carta indicaba claramente que antes de desplazarse al reino valenciano para resolver las cuestiones que habían quedado pendientes en Monzón también debía hacerlo al territorio aragonés para celebrar allí unas Cortes propias.

En efecto, el monarca permaneció en Zaragoza de forma ininterrumpida desde el 16 de febrero hasta el 21 de marzo de 1290 (Carreras 1921: 78), 
clausurando la asamblea hacia el día 11, cuando se hizo pública su promesa de observar una «protestationem» realizada por los nobles y las villas de Aragón. En concreto, en ella se detallaban las condiciones bajo las cuales los aragoneses - incluyendo los dominios de la Iglesia - estaban dispuestos a pagar el subsidio que se había prometido al rey en la reunión parlamentaria, que eran esencialmente iguales a las de la carta de indemnidad del subsidio catalán y mallorquín de noviembre de 1289: los tres estamentos concedían «certum auxilium» voluntariamente, «ex mera liberalitate», y "pro deffensione terre nostre in guerra quam habemus cum rege Francie et aliis», también durante tres años, a no ser que la guerra acabara antes, y, por otras referencias a los diputados colectores y clavarios que se nombraron «ad ponendum et colligendum cisam sive adiutorium», parece que se trataba igualmente de una sisa o imposición indirecta general en los mercados. ${ }^{34}$ No obstante, se especificaba claramente que el auxilio se regiría «secundum modum et formam ordinatam et taxatam per eosdem in ista Curia», la de Zaragoza, lo que lo desvinculaba del subsidio que se había aprobado en la reunión de Monzón. Así se constata, por ejemplo, en sus plazos: no se debía comenzar a pagar hasta la Pascua de 1290 — el 2 de abril—, cuatro meses más tarde que la ayuda de los catalanes y mallorquines. Además, la última condición de la protesta aragonesa, aceptada por Alfonso el Liberal, indicaba que en aquellas Cortes de Zaragoza se habían aprobado ciertas ordenaciones, en virtud de las cuales se exigía:

Quod statuta omnia alia et ordinationes que sunt per eos facta in ipsa Curia circa pacem et iustitiam tenendam, et ordinatio seu statutum factum per eos in ista Curia de inquisitione facienda in furto, ropparia et homicidio, ut in ipsa ordinatione continetur, valeat hinc ad festum Resurrectionis Domini et deinde usque ad tres annos continue completos, et ex tunc volunt quod ipsa statuta seu ordinatione sint cassa, vana et irrita ac si nunqua in aliquo essent facta, et quod deinceps sint eis suis dicto regno et cunctis salvi fori sui. ${ }^{35}$

Por lo tanto, ciertamente se aprobaron una serie de disposiciones sobre paz y justicia, así como una inquisición general — probablemente de los oficiales reales-, de las que no tenemos más detalles, ya que por su carácter extraordi-

34 La protestación en: ACA, RC, reg, 83, ff. 27r-28v (11-III-1290), transcrita por González Antón (1975: doc. 273). La cita sobre los diputados en: ACA, RC, reg. 85, f. 9v (16-IV-1290). De hecho, muchos otros documentos de dicho registro, el 85, contienen indicaciones sobre la sisa recaudada en Aragón.

35 ACA, RC, reg, 83, f. 28r (11-III-1290), transcrito por González Antón (1975: doc. 273) 
nario solo debían estar vigentes durante los tres años posteriores, de manera que no pasaron definitivamente al cuerpo foral aragonés. Por otra parte, cabe indicar que dicha inquisición sobre los cargos probablemente había sido pactada de forma general en Monzón, ya que se acabó produciendo en todos los territorios de la Corona, aunque en Aragón y en Valencia solo comenzó cuando el rey se trasladó a dichos reinos y fueron aprobados subsidios y acuerdos propios de manera particular. ${ }^{36}$ En resumen, pues, a pesar de que hubo representantes de los estamentos aragoneses en Monzón entre octubre y noviembre de 1289, la concreción de la negociación político-fiscal con Alfonso el Liberal no se produjo allí, sino cuando el rey se trasladó a Zaragoza y celebró Cortes particulares del reino de Aragón entre febrero y marzo de 1290, en las que se sancionaron diversas disposiciones temporales y se otorgó un donativo. Lo mismo que también sucedería en el reino de Valencia.

\subsection{La asamblea valenciana de la ciudad de Valencia} (septiembre de 1290)

El caso de los valencianos respecto a las Cortes Generales de Monzón fue análogo al que hemos explicado para los aragoneses, aunque en este caso no se encuentra en la documentación ninguna mención explícita sobre la celebración de una Corte o Parlamento, en consonancia con la negativa de la nobleza del reino a legitimar el marco institucional valenciano durante aquella época. Por el contrario, como hemos visto, el monarca simplemente había comunicado, tanto a los prohombres de la ciudad y las villas reales como a los magnates aragoneses, que iría a tierras valencianas para tratar «super facto regni Valentie» y sobre las graves «altercationes» entre unos y otros que se habían manifestado en la reunión de Monzón. Por otra parte, a pesar de haber prometido que acudiría primero en febrero y después tras la clausura de las Cortes aragonesas, que finalizaron en marzo de 1290, nuevamente la previsión del rey se demoró por las circunstancias políticas, ya que en abril tuvo que asistir a una entrevista con el príncipe de Salerno entre La Jonquera y Panissars y posteriormente pasó los meses de mayo y junio entre Barcelona y Montblanc (Zurita, 1610: Libro IV, cap. 118; Carreras, 1921: 79-80; Soldevila, 1963: 340). Finalmente, a principios de julio Alfonso el Liberal entró en el reino de Valen-

36 Sobre las inquisiciones iniciadas en Cataluña inmediatamente después de las Cortes de Monzón cuando también se puso en marcha el subsidio catalán— dan noticias tanto Klüpfel (1929-1930: 325 326) como el mismo González Antón (1975: doc. 269). 
cia y solo entonces, ocho meses después de la aprobación del subsidio catalán en Monzón y cuatro de la del aragonés en Zaragoza, se puede documentar la primera referencia a un «auxilii sive sise» que se debía recaudar en tierras valencianas, aunque se hablaba en futuro y las noticias al respecto aún tardarían en multiplicarse. ${ }^{37}$

En concreto, el rey permaneció de manera prácticamente ininterrumpida durante dos meses y medio en la ciudad de Valencia, entre julio y mediados de septiembre de 1290. Sin embargo, su rastro documental por lo que respecta a los asuntos valencianos es escaso durante los meses de julio y agosto, como muestran las noventa órdenes diversas - asignaciones, reconocimientos de deuda, gestión de rentas, causas judiciales, donaciones de tierra, ventas de patrimonio, nombramiento de oficiales, etc. - que catalogó Rafael Gallofré en la cancillería real durante dicho período (1968: docs. 1617-1707). En cambio, en contraste con dicha cifra, el mismo catálogo muestra durante los nueve primeros días de septiembre más de cien órdenes, lo que a todas luces manifiesta algún tipo de acto extraordinario, que intensificó la expedición de disposiciones. Y efectivamente por entonces, tal vez entre el 3 y el 9 de septiembre de 1290 - cuando se concentran más de noventa documentos - tuvo lugar algún tipo de asamblea estamental o cuando menos de congregación de las universidades reales $-\mathrm{y}$ probablemente de parte de la nobleza de origen aragonés - en que se desarrollaron las cuestiones que habían quedado pendientes en Monzón y, a su vez, Alfonso el Liberal impuso la observancia del fuero de Aragón en el reino de Valencia, lo que mantuvo la cuestión foral en unos parámetros relativamente estables hasta las Cortes valencianas de 1329-1330 (Baydal 2016).

No en vano, el 2 de septiembre de 1290 el rey ordenó a los justicias, bailes y notarios de Morvedre, Xàtiva, Alzira, Gandia y el resto de villas reales que fueran al día siguiente a Valencia para que jurasen respetar los Fueros de Aragón a los «richis hominibus, militibus, infançonibus et hominibus castrorum et locorum suorum», tal como había ordenado Pedro el Grande - haciendo referencia al Privilegio General aragonés de 1283- y como acababan de jurar el justicia y todos los notarios de la ciudad de Valencia. ${ }^{38}$ Así,

37 Se trataba de una asignación de 13.000 sueldos al mercader Jaume Carbonell, que los debía recibir «de primis denariis quos recipi et colligi faciamus in regno Valentie, qualibet ratione vel causa a christianis, iudeis vel sarracenis, etiam de denaris auxilii sive sise que nunc nobis dari debent in regno predicto»: ACA, RC, reg. 82, ff. 61v-62r (8-VII-1290).

38 ACA, RC, reg. 81, f. 174r (2-IX-1290). 
en efecto, el 3 de septiembre Alfonso el Liberal reconocía al conjunto de núcleos reales que, a pesar de que acabaran de jurar el cumplimiento de las leyes aragoneses a aquel colectivo en concreto, la teórica vigencia exclusiva de los Fueros de Valencia en todo el reino promulgada en tiempos de Jaime I continuaba manteniendo su valor. En cualquier caso, la medida suponía una victoria de la Unión aragonesa frente a las pretensiones iniciales de la Corona y las del estamento real del reino de Valencia, que, según se decía explícitamente, se veía obligado a aceptar aquella «impositio seu inductio» ordenada por el rey «de foro Aragone supradicto in dictam civitatem et regnum $» .{ }^{39}$ En definitiva, las amenazas realizadas por parte de los unionistas en marzo de 1289 de atacar a «los rebelles del regno de Valençia» tuvieron su efecto un año y medio más tarde, después de que los nobles aragoneses y los prohombres valencianos se hubieran enfrentado gravemente en las Cortes de Monzón.

Por otra parte, también entonces, a partir del 5 de septiembre de 1290, comenzó una inquisición contra los oficiales, servidores, escribanos y recaudadores reales del reino de Valencia, en consonancia con las que se habían iniciado en Cataluña al acabar las Cortes de Monzón de 1289 y en Aragón tras las Cortes de Zaragoza de $1290 .{ }^{40}$ Igualmente, el mismo día, de manera casi inmediata al juramento del fuero aragonés, el rey requirió cantidades monetarias a todos los núcleos del realengo y también a los lugares eclesiásticos del reino, ${ }^{41}$ mientras que la nobleza probablemente quedó exenta de dicho subsidio a la Corona, como había sucedido en el territorio valenciano desde tiempos de la conquista, precisamente a causa de la disputa foral (Baydal 2014). En este caso, no obstante, a diferencia de lo que sucedió en tierras catalanas y aragonesas, en que, como hemos visto, se debió imponer una sisa o imposición indirecta general, gestionada por unos diputados colectores y unos clavarios escogidos por los estamentos, todo apunta a que la contribución valenciana consistía en un tributo directo recaudado de manera individual por cada uno de los miembros del brazo real y de la Iglesia, que traspasaban el dinero a los porteros y el tesorero del rey. No en vano, aquí Alfonso el Liberal realizó peticiones de cantidades concretas a los municipios del realengo y a cada señor o cuerpo eclesiástico, por un valor total de 154.000 sueldos en el primer

39 ACA, RC, reg. 83, f. 88v (3-IX-1290).

40 Véanse numerosas órdenes al respecto en: ACA, RC, reg, 81, ff. 183v-185r (5-IX-1290) y 189v (7-IX1290); reg. 82, ff. 83r (20-IX-1290) y 90r-v (28-XI-1290).

41 ACA, RC, reg. 82, ff. 67r-68r (5-IX-1290). 
caso y de 187.000 sueldos — posteriormente rebajados a 136.000 por ciertas remisiones - en el caso de los prelados. ${ }^{42}$

De hecho, a pesar de que la petición real hablaba de un «auxilium sive cisam [sicut] in aliis terris nostris nobis concessa est», ${ }^{43}$ lo cierto es que muchos otros indicios, aparte de las cantidades exactas pedidas a cada miembro de los estamentos, señalan que se trataba de un tributo directo repartido en proporción al patrimonio familiar o personal. ${ }^{44}$ En este sentido, un documento dirigido a todos los «collectoribus redemptionum cise civitatis et regni Valentie» probablemente se aproxima más, con dicha expresión, ${ }^{45}$ al significado real del subsidio en el territorio valenciano, dado que las cantidades solicitadas se pagaban para redimir el auxilio o sisa que inicialmente se había acordado en Monzón por parte de todos, pero que no se había concretado en una forma impositiva u otra hasta la aprobación de las disposiciones negociadas de manera separada, primero con los catalanes y mallorquines en Monzón, después con los aragoneses en Zaragoza y finalmente con los valencianos en Valencia. Asimismo, otros documentos también apuntan en esta dirección, como una orden a las autoridades de Morella sobre la cantidad a pagar «pretextu çise ordinate in Curia Montissoni» ${ }^{46}$ o la admisión real de la protesta realizada por la ciudad de Valencia, que alegaba ser franca por privilegio de toda «questia sive peyta vel alio servitio», por lo que Alfonso el Liberal tuvo que reconocer que recibía su «donum» de 80.000 sueldos «gratis et non aliqua obligatione», manteniendo indemne su exención y prometiendo que no realizaría ninguna otra petición de ningún tipo durante dos años, «ratione aiude seu sise quam

42 Los veinte núcleos reales a los que se requirió dinero (Valencia, Morella, Xàtiva, Morvedre, Gandia, Onda, Burriana, Dénia, Llíria, Alzira, Alpuente, Ademuz, Castielfabib, Vila-real, Montesa, Cocentaina, Alcoi, Penàguila, Guadalest y Pego) probablemente también recibieron rebajas, pero no se anotaron en el registro cancilleresco (solo una de 2.000 sueldos a Ademuz). Por lo que respecta al estamento eclesiástico, se realizaron peticiones de cantidades al obispo y el capítulo de la sede de Valencia; los canónigos y clérigos del obispado de Segorbe; los clérigos del obispado de Tortosa con lugares y bienes en el reino de Valencia; los comendadores de las órdenes del Temple, el Hospital, Calatrava y Uclés; Vilafamés y la comanda de Cervera, de la misma orden del Hospital; Xivert, Miravet, Albalat y Cabanes, de la orden del Temple; Quart y Castellón de la Plana, del monasterio de Poblet, y Almassora, del obispo de Tortosa.

43 ACA, RC, reg. 82, f. 67v (5-IX-1290).

44 Por ejemplo, el monarca tuvo que ordenar una exención especial en el «auxilii sive cise» para los miembros de la casa real habitantes en la ciudad de Valencia que quedaban habitualmente libres del pago «in contributionibus questiarum seu aliarum exactionum nostre», que se recaudaban mediante tallas directas: ACA, RC, reg. 82, f. 92r (28-XII-1290).

45 ACA, RC, reg. 82, f. 92v (28-XII-1290).

46 ACA, RC, reg. 81, f. 226v (1-XII-1290). 
propter deffensione terre nostre habemus et habere debemus de aliis terris nostris [...] iuxta ordinationem Curie Montissoni vel aliorum locorum terre nostre». ${ }^{47}$

En definitiva, aquella cisa valenciana de 1290 no era tal, sino que simplemente recibió dicha denominación por analogía terminológica con las imposiciones indirectas que se estaban cobrando en Cataluña y Aragón para recaudar las ayudas acordadas en Monzón - en el caso aragonés puesta en marcha unos meses después, tras su aprobación definitiva en unas Cortes propias. Por el contrario, el estamento real y el eclesiástico del reino de Valencia — dejando fuera al nobiliario, tradicionalmente exento - debieron pagar un subsidio colectado mediante un impuesto directo de repartición, que seguía el uso de las habituales questias o peitas (Baydal, 2011).

\section{Conclusiones: unas Cortes Generales de Monzón mal entendidas}

Vistos en conjunto los precedentes y el ciclo de asambleas celebradas entre 1289 y 1290, así como el desarrollo de las negociaciones y subsidios correspondientes, ¿podemos decir que aquellas Cortes de Monzón fueron las primeras Generales de la Corona de Aragón, como ha afirmado la historiografía tradicionalmente y como, al parecer, aseveraba Pedro el Ceremonioso casi un siglo después? Seguramente sí. En este sentido, cabe apuntar que, sin lugar a duda, ya existieron otras asambleas generales a las que fueron convocados miembros de los estamentos de los diversos territorios de la Corona a finales del reinado de Jaime I, comenzando por las de Lérida de 1272. Pero al mismo tiempo, por la asistencia un tanto aleatoria, sus objetivos estrictamente circunstanciales y su corto desarrollo, también cabe apuntar que dichas reuniones no tenían aún las características que comenzarían a definir plenamente las Cortes justo a partir de la década de 1280. En cambio, las de 1289 tuvieron probablemente una asistencia mucho más generalizada y representativa aunque no hay que olvidar que el estamento nobiliario valenciano aún no se había constituido de manera separada del aragonés, a causa de la disputa foral, lo que ya no ocurría en absoluto en las siguientes asambleas generales de Monzón a partir de 1362 - y los temas a tratar ya tenían un carácter plena- 
mente parlamentario, de resolución mancomunada de problemas que afectaban al conjunto de la Corona y que requerían de una intensa negociación político-fiscal con las comunidades de cada territorio.

No obstante, justo aquí subyace el gran error de comprensión sobre las Cortes Generales de Monzón de 1289 que se ha reproducido tradicionalmente: a pesar de que se debieron aprobar algunos principios de acuerdo generales, como el inicio de inquisiciones a todos los oficiales reales de la Corona o la concesión de subsidios para la guerra por parte de los estamentos, ${ }^{48}$ las negociaciones solo alcanzaron materialización allí para el caso de los catalanes y los mallorquines, que eran los únicos a los que afectaban las constituciones y los capítulos de la ayuda económica aprobados en dicha villa del reino de Aragón. Por el contrario, posiblemente como consecuencia de las profundas desavenencias mostradas por los aragoneses y los valencianos por la gravedad del mencionado conflicto foral, el desarrollo de las negociaciones con las voces políticas de dichos reinos, a diferencia de lo que pasaría en las sucesivas Cortes Generales de Monzón, no tuvo lugar allí mismo, sino que fue pospuesto para reuniones privativas que tuvieron lugar meses después: las Cortes de Zaragoza de febrero a marzo de 1290 y una asamblea en Valencia por septiembre de 1290. Es así, en plena consonancia con el contexto político de la época, como debemos entender dicha primera convocatoria general, que décadas más tarde tendría continuidad con las convocatorias de Pedro el Ceremonioso, sucedidas por muchas otras hasta entrado el siglo XVII.

\section{Referencias bibliográficas}

BAYDAL, Vicent (2011), «Peites, quèsties, redempcions d'exèrcit i subsidis: la naturalesa i l'evolució dels principals tributs reials directes a la Corona d'Aragó des de

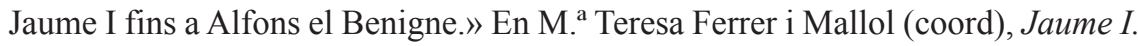
Commemoració del VIII centenari del naixement de Jaume I. Barcelona, Institut d'Estudis Catalans: 259-285.

BAYDAL, Vicent (2014), Guerra, relacions de poder i fiscalitat negociada: els orígens del contractualisme al regne de València (1238-1330). Barcelona, Fundació Noguera

48 Seguramente también se debió acordar una reordenación de las rentas reales, en consonancia con la revocación de las donaciones realizadas desde el inicio del reinado, según se desprende de diversos inventarios de 1289 que incluyen anulaciones de asignaciones ordenadas por la «Curiam Montisoni»: ACA, RC, Varia, núm. 405, Cuadernos $1^{\circ}$ y $3^{\circ}$. 
BAYDAL, Vicent (2016), Els valencians, des de quan són valencians? Catarroja, Afers.

CARRERAS, Francesc (1921), «Itinerari del rey Anfós II «lo Liberal» (1285-1291)», Boletín de la Real Academia de Buenas Letras, 71: 61-83

Cingolani, Stefano M. (2010), Pere el Gran. Vida, actes i paraula. Barcelona, Base.

DE LA TORRE, Antonio (1923), Discurso leido en la Real Academia de Buenas Letras de Barcelona: Orígenes de la «Deputació del General de Catalunya». Barcelona, Atlas Geográfico.

FITA, Fidel y Oliver, Bienvenido (1896), Cortes de los antiguos reinos de Aragón y de Valencia y principado de Cataluña publicadas por la Real Academia de la Historia. Madrid, Establecimiento tipográfico de la viuda e hijos de Manuel Tello, tomo I.

FONDEVILLA, Fernando (1913), «La nobleza catalanoaragonesa capitaneada por Ferrán Sánxez de Castro en 1274.» En Congrés d'Historia de la Corona d'Aragó dedicat al rey en Jaume y a la seua època, Barcelona, Ayuntamiento de Barcelona: 1061-1168.

GALlofré, Rafael (1968), Documentos del reinado de Alfonso III de Aragón: relativos al antiguo reino de Valencia y contenidos en los registros de la Corona de Aragón. Valencia, Institución Alfonso el Magnánimo.

GonzÁlez Antón, Luis (1975), Las Uniones aragonesas y las Cortes del reino (1283-1301). Zaragoza, Escuela de Estudios Medievales.

GonZÁlez AnTón, Luis (1978), Las Cortes de Aragón. Librería General, Zaragoza.

GONZÁLEZ ANTÓN, Luis (1979), «Notas acerca de la evolución preparlamentaria en Aragón en el reinado de Jaime I.» En Jaime I y su época. X Congreso de Historia de la Corona de Aragón. Zaragoza, Institución Fernando el Católico: 415-429.

KLÜPFEL, Ludwig (1929-1930), «El règim de la Confederació catalano-aragonesa a finals del segle XIII», Revista Jurídica de Catalunya, 35-36: 195-226, 289-327 y 298-331.

PALACIOS, Bonifacio (1975), La coronación de los reyes de Aragón 1204-1410. Aportación al estudio de las estructuras políticas medievales. Valencia, Anubar.

Romeu, Sylvia (1969), «Cortes de Valencia de 1281», Anuario de Historia del Derecho Español, 39: 725-728.

Romeu, Sylvia (1970), «Catálogo de Cortes valencianas hasta 1410», Anuario de Historia del Derecho Español, 40: 581-608.

Romeu, Sylvia (1972), «Los Fueros de Valencia y los Fueros de Aragón», Anuario de Historia del Derecho Español, 42: 75-116.

SABATÉ, Flocel (2009), «Estamentos, soberanía y modelo político en la Cataluña bajomedieval», Aragón en la Edad Media, 21: 245-278.

SÁNCHEZ, Manuel (1995), El naixement de la fiscalitat d'Estat a Catalunya: segles $X I I-X I V$. Girona, Eumo.

SÁnchez, Manuel y ORTí, Pere (1997), Corts, Parlaments i fiscalitat a Catalunya. Els capitols del donatiu (1288-1384). Barcelona, Generalitat de Catalunya. 
SANTAMARÍA, Álvaro (1982), «Tensión Corona de Aragón-Corona de Mallorca. La sucesión de Sancho de Mallorca (1318-1326)», En la España medieval, 3: 423496.

SoldeVIla, Ferran (1955) Jaume I. Pere el Gran. Barcelona, Teide.

Soldevila, Ferran (1956), Pere el Gran. Primera part: l'infant. Barcelona, Institut d'Estudis Catalans, vol. III.

SoldeVIlA, Ferran (1963), Vida de Pere el Gran i d'Alfons el Liberal. Barcelona, Aedos.

SOLDEVILA, Ferran (2007), Les quatre grans cròniques: I. Llibre dels feits del rei en Jaume. Barcelona, Institut d'Estudis Catalans.

ZURITA, Jerónimo (1610), Los cinco libros primeros de la segunda parte de los Anales de la Corona de Aragón. Zaragoza, Juan de Lanaja y Quartanet. 
